\title{
Entrevista com Marlene Goidanich
}

\section{*Cláudia Muller Sachs}

Resumo

Entrevista com a professora de voz e musicista Marlene Goidanich, na qual ela relata sua experiência no Departamento de Artes Dramáticas da UFRGS, onde promoveu a mudança de enfoque no trabalho do ator, passando do uso de técnicas herdadas do canto lírico para a preocupação com a saúde e a expressão vocal como um todo. Coordenadora do Conjunto de Câmara de Porto Alegre, ela conta também sobre suas influências, sua trajetória artística e seu pensamento sobre o trabalho vocal.

Palavras-chave: expressão vocal - ator voz - canto

\begin{abstract}
Interview with voice professor and musician Marlene Goidanich, in which she describes her experience in the Department of Performing Arts at UFRGS, where he promoted the change of focus in the actor's work, leaving the use of techniques inherited from classical singing to be concerned with the actor's health and expression as a whole. Coordinator of the Porto Alegre Chamber Ensemble, she also talks about her influences, her artistic career and her thoughts on the vocal work.
\end{abstract}

keywords: vocal expression - actor - voice singing 
MARLENE HOFMANN GOIDANICH atua desde 1964 na recriação de Música Antiga no sul do país, participando do Conjunto de Câmara de Porto Alegre desde sua fundação em 1969 e sendo coordenadora deste grupo de 1978 a 2006. Foi professora de voz no Departamento de Arte Dramática do Instituto de Artes da Universidade Federal do Rio Grande do Sul de 1986 a 2001. Tem feito a preparação vocal de inúmeras peças teatrais, ministrou diversas oficinas de "Educação da Voz" para atores, cantores e profissionais da área. Participou de vários Encontros de Música Antiga, no Paraná, Rio de Janeiro e Minas Gerais. Sob sua coordenação o Conjunto de Câmara de Porto Alegre recebeu recebeu Prêmio Açorianos de "Melhor Trabalho de Música Erudita" em 1992, 1997, 2004 e, em 2003, o Troféu de “Destaque Especial” pelo conjunto da obra. Representou o Brasil em diversas ocasiões.

Referência como professora de voz para uma vasta legião de artistas de teatro do Rio Grande do Sul, Marlene segue viva em nossa memória e nossa prática teatral. Nessa feliz oportunidade de ser recebida em sua casa para essa entrevista, ela nos conta um pouco de sua experiência no DAD, suas influências, vivências e pensamentos desenvolvidos ao longo desses anos de intensa dedicação à música e às artes cênicas. No dia 27 de janeiro de 2015, em Porto Alegre, Goidanich foi entrevistada por Cláudia Sachs.

ENTREVISTADORA - Querida professora Marlene, gostaríamos que você nos falasse sobre seu trabalho de voz, principalmente aquele com atores.

MARLENE - Bom, existem, naturalmente, inúmeras possibilidades de trabalho de voz. Linhas diferentes de trabalho de voz. Eu sempre me preocupei em trabalhar a voz mais natural, me preocupando com a saúde vocal das pessoas. Eu já tinha esse trabalho com o Conjunto de Câmara de Porto Alegre fazendo música antiga onde se usava para música medieval e renascentista uma voz natural. O vibrato, do canto lírico, começou somente no período barroco como ornamento para notas longas. Eu penso que cada voz tem uma conotação diferente, e justamente aquilo que é diferente em cada voz é que deveria ser preservado. Não moldar vozes dentro de uma técnica, mas fazer um trabalho de conscientização, que eu sempre fiz. Em primeiro lugar, alongamentos e conscientização postural, porque isto é que vai trazer a conscientização da respiração correta. A respiração natural, que normalmente nós perdemos ao longo dos anos. E depois a conscientização do trajeto, do caminho da voz. Essa abertura interior para as vogais. O trabalho já mecânico, exterior, das consoantes. O trajeto da voz, a abertura interior e o apoio correto para que a voz possa ser emitida de uma forma natural, mas para ser ouvida com apoio num ambiente um pouco maior, digamos. Então, no inicio de 1986, eu tinha muitos alunos particulares, que eram alunos adiantados do DAD, fazendo aula comigo na minha residência. Então recebi o chamado da professora Irene Britzke lá para o DAD, e a professora Maria da Graça Nunes disse: "olha, todos os alunos já estão tendo aulas particulares contigo na tua residência! Nós queremos que tu dês aula aqui!" O que acontecia naquela época? Os alunos do DAD faziam só técnica vocal no Departamento de Música. Aí, claro que o enfoque era para o canto lírico italiano, que não tinha muito a ver com a linha de teatro. Bom, aí eu criei seis disciplinas que ainda não existiam. Criei as súmulas, conteúdos programáticos, e comecei a lecionar Expressão Vocal para Teatro I, II, III, IV e Prática de Canto para Teatro I, II. Então os alunos tinham seis semestres comigo, coitados (risos). Dizia minha filha psicóloga: "Coitados, mãe!" Mas eu acredito que, naquela época, tiveram pelo menos uma base sólida. O que eu fiz? Na época, em 1960 e pouco, eu tinha aulas com Armando Albuquerque, Bruno Kiefer, maestro Oscar Zander, a professora Débora Katz, aulas particulares. E fazia morfologia e história da música com Bruno Kiefer. Conversei muito com ele, e lhe disse o seguinte: "Eu vou tentar cantar com os alunos músicas escritas para o teatro e não o canto lírico italiano, o bel canto, que estava sendo ensinado, naquela época, no Departamento de Música. Então, no primeiro semestre, Expressão Vocal para Teatro I. Eu tinha sempre dois encontros semanais, cada encontro de dois períodos seguidos. O primeiro encontro semanal eu tentava direcionar para a voz falada, e o segundo encontro semanal eu tentava direcionar para a voz cantada. A meu ver, a colocação da voz é muito mais fácil e mais rápida através do canto, e não só através da fala. Mas a voz falada e a cantada devem ser trabalhadas juntas, como um todo. Assim como a gente deveria trabalhar junto corpo e voz que, naquela época, era bastante dissociado. Não havia interdisciplinaridade entre as disciplinas no DAD. Bom... Então no primeiro semestre, Expressão Vocal para Teatro I, eu fazia mais Idade Média. Nós líamos num primeiro encontro, peças como "A Sabedoria” de Rosvita Von Gandersheim do século X. E claro que trabalhando sempre aquele enfoque de colocação e abertura interior para as vogais. Eu usava exercícios de Tai-chi-chuan com som que, naturalmente, se meu mestre na época soubesse disso... (risos) Não tem nada a ver, tai-chi não é com som, mas eu associava vogais aos exercícios de tai-chi porque isso facilitava à pessoa ter mais domínio sobre a respiração. Principalmente o controle de sopro com som. E o 
segundo encontro semanal, no primeiro semestre, a gente cantava música medieval, ou seja, eu começava com fragmentos de canto gregoriano, que eram a base para os dramas litúrgicos do século XII. Depois cantávamos cenas de dramas litúrgicos do século XII, fazíamos cenas cantadas de peças profanas como Le jeu de Robin et Marion de Adam de la Halle, que era um trouvere francês. Cantávamos também danças sapateadas, cantatas como "Calenda Maia”, por exemplo. Então fazíamos músicas mais direcionadas para o teatro e nas línguas originais: latim, francês antigo, provençal, italiano antigo, enfim... No segundo semestre eu direcionava mais para a região da Renascença. Naturalmente eu pensava que talvez fossem feitas cenas no DAD de Cervantes, de Gil Vicente, de Commedia dell'arte italiana..., mas não era bem o caso. Me lembro que quando eu cantava no madrigal da UFRGS com Madeleine Ruffier nós fizemos a primeira commedia dell'arte aqui em Porto Alegre, no palquinho do DAD, que agora é a Alziro Azevedo. Era a comédia "La Pazzia Senile" de Adriano Banchieri, de 1606. E eu cantava no madrigal, que eram seis vozes solistas: soprano, meio-soprano, contralto, tenor, barítono baixo, regido por Madeleine Ruffier num estrado no fundo do palco e era feita uma mímica dessa commedia dell'arte cantada com malhas pretas e meias máscaras de papel machê, com adereços de papel machê... Entre os alunos que estavam ali se apresentando estava o Luiz Arthur Nunes, a Nara Keiserman, dirigidos por Maria Helena Lopes.

E - Olha, que bacana!

M - É. Eu pensava “eles devem fazer commedia dell'arte”, mas eu não via nada daquilo. Bom, mas nós tentávamos cantar no segundo semestre o início da Renascença portuguesa, espanhola, cenas de commedia dell'arte italiana, Renascença inglesa, para Shakespeare, sempre tentando direcionar, e sempre em línguas originais. No terceiro semestre, nós começávamos no barroco. Primeiro período barroco, segundo período barroco, o que poderia ser aproveitado, de repente, para Moliére... Na parte da Renascença, até dançávamos uma pavana! Fazíamos toda a coreografia. Eu tinha esse material por causa do Conjunto de Câmara de Porto Alegre, que foram trinta e seis anos ininterruptos.

$\mathbf{E}-$ De pesquisa...

$\mathbf{M}$ - É, de pesquisa. Enfim, terminei em 2006 com o conjunto. Eu comecei a cantar com Madeleine Ruffier que era uma regente de origem francesa, uma mulher muito a frente da época, em 1964.

\section{E - Quando eu nasci! (risos)}

M- Mas eu nasci em 1944! Nessa época eu já estudava canto, e posso dizer assim que quem me deu a base maior de técnica vocal para o canto foi o professor José Dantas Pimentel, que já era uma pessoa octogenária. Ele era um general reformado do exército, que domava cavalos (risos), algo bem estranho... Mas na sua juventude ele esteve no Rio, tendo aulas com os grandes cantores de ópera, que vinham da Itália lá para o Rio de Janeiro. Ele me deu uma boa base técnica, o general. E depois, quem me abriu portas e janelas para um trabalho diferenciado de voz foi o pedagogo alemão Theophil Maier. Eu assisti ele no Trio Exvoco em 1980, pelo Instituto Goethe, e pedi encarecidamente ao diretor Kurt Sharf que trouxesse esse homem para dar cursos de voz. Traduzi todos os cursos de voz dele para o Instituto Goethe, porque alemão foi a minha língua materna que eu falava desde a infância na família. E realmente este homem me abriu portas e janelas. Ele trabalhava no Trio Exvoco, já tinha mais de cinqüenta anos na época, em 1980, e trabalhava textos dadaístas, concretistas, coisas que eu aproveitei muito depois no DAD com os alunos, principalmente na parte de voz falada. Nós fazíamos improvisações sobre textos de poesia concreta. Os irmãos Campos, até os modernos russos! Se fazia muito dadaísmo, concretismo e improvisações sonoras na parte de voz falada. E a cantada no segundo encontro. No terceiro semestre, entrávamos no barroco, também em varias línguas: inglês, italiano, francês. E no quarto semestre, entrávamos mais na linha contemporânea. Eu fiz uma pesquisa grande na Biblioteca Nacional do Rio de Janeiro e encontrei lá música para o teatro do século XIX e XX, do teatro musicado. Então cantávamos Chiquinha Gonzaga e coisas assim também. Além de, naturalmente, Erik Satie, coisas diferenciadas em outras línguas. Isso aí é que depois eu fui aprimorando...

E - Satie com letra?

M - Sim! Eu tinha três canções de Satie que eu cantava no DAD. Três lindas canções, que nós fazíamos em francês. Enfim, era um repertório vasto porque eu tinha tanto da parte de canto, minha, quanto do Conjunto de Câmara de Porto Alegre. O que eu estava dizendo é que em 1964 eu entrei, então, no Coral de Câmara 
da Filosofia da URGS, que Madeleine Ruffier regia. Não era federal ainda, era URGS. Aí o que se fazia? Porque eu tinha esse repertório todo? Fazíamos Renascença, Contemporâneo brasileiro e folclore brasileiro. Em 1964, no início, eu tive uma experiência muito interessante conhecendo a música renascentista com o maestro Isaac Karabtchevsky, que era colega de Madeleine Ruffier. Conheci, então, a renascença inglesa e adorei aquele mundo antigo! Nas aulas de canto eu fazia música de Câmara, mas música de câmara alemã. Era Schubert, Schumann, Mendelssohn,... E aí, eu conheci um mundo novo de música antiga, de música Renascentista. Em 1965, Madeleine Ruffier criou o madrigal da URGS comigo e mais... nós éramos seis cantores, solistas. Era muito incrível porque naquela época se tinha mais tempo! Nós ensaiávamos no porão da rádio da universidade todas as noites das 20 horas às 24 horas! Isso era normal, e ninguém recebia nada! O que nós fizemos então? No madrigal ela começou a ir a dois extremos: procurar as raízes da música ocidental. Na música medieval, fazíamos Iacobo da Bolonha, de Firenzi... meu Deus! Cantávamos Guillaume de Machaut, quer dizer, música medieval mesmo. E música contemporânea na época, isso era 1965, que eram ciclos de Debussy, Ravel, Hindemith, o que muitos corais hoje em dia ainda não fazem. Era realmente um repertório muito seleto e muito estranho para o nosso público, porque a Madeleine gostava de chocar um pouco o público. Então ela vinha com aquelas músicas medievais estranhíssimas, digamos, em clubes em Caxias do Sul! O público saía bastante espantado, mas ela dizia: "Ninguém pode gostar daquilo que não conhece! Nós temos que trazer o novo para eles poderem avaliar se gostam daquilo". Então isto foi uma escola muito grande! Madeleine morreu em 1973. E desde 1966 eu participava do Quarteto de Flautas Doces de Izolde Frank, que era uma grande pedagoga alemã com a qual eu estudava flauta doce. Tínhamos, então, o nosso quarteto. Em 1969, esse Quarteto de Flautas Doces foi aumentado para fazer música barroca com baixo contínuo, cravo, violoncelo, flauta transversal, e eu cantava também nesse grupo. Aí foi denominado e criado o Conjunto de Câmara de Porto Alegre. Então existia de 1969 esse nome, até 2006. Em 1978, ela desistiu, ficou só com a parte pedagógica dela lá em Canoas e eu peguei a coordenação.

$\mathbf{E}$ - Desde que ano?

M - 1969. O Conjunto de Câmara de Porto Alegre.

E - Nossa! Precisa uma pesquisa sobre isso, não é mesmo?

M - Veja. Eu tenho dezenas de pastas de relatórios aqui em casa. Pastas de correspondência, que naquela época ainda não havia computador, email... Cartas interessantes de pessoas que já faleceram. Eu tenho uma memória cultural de quarenta anos aqui e não sei o que fazer com isso! Ainda estou com os instrumentos antigos todos aqui. Pensei, primeiro, em fazer alguma doação, mas não encontrei uma entidade que realmente valesse a pena. Estão até dizendo aí que eu deveria vendê-los, enfim... Então é só para ter uma idéia da continuidade.

Durante doze anos no DAD, eu era a única professora de voz. Dando Expressão Vocal para Teatro I, II, III, IV e Prática de Canto para Teatro I, II. Depois entrou Gisela Habeyche, que foi também minha aluna no DAD, e outras pessoas. Eu dei aula durante dezesseis anos lá. De 1986 até agosto de 2001. E continuo ainda fazendo preparação vocal de grupos teatrais, geralmente antigos alunos que me colocam nos projetos. E alguns atores, como Sandra Dani, que volta e meia faz aula comigo... adoro ela! E claro que eu trabalho mais tempo, com continuidade, com a Usina do Treinamento do Ator, que são maravilhosos, Ciça Reckziegel, Gisela Habeyche, Celina Alcântara, Gilberto Icle que foram todos meus alunos do DAD. E também trabalhei com Viviane Juguero, em suas peças infantis.

E - Então a gente pode ir te chamando para os projetos?(risos)

M - Sim! O ano passado eu ainda participei de dois. Eu ajudei na preparação vocal dos atores de "Os Homens do Triangulo Rosa” da Margarida Peixoto. E a pianista Elda Pires, ela era minha musicista durante doze anos no Conjunto de Câmara de Porto Alegre.

E - Ela é bárbara!

$\mathbf{M}$ - Ahh. Muito cantei dando concertos com ela. Com ela e com Celso Loureiro Chaves, que também participou do conjunto. 
E - Marlene, eu me lembro quando eu era tua aluna e nós fazíamos exercícios em que nós passeávamos com as vogais, com os sons. Me lembro que tinha uma ideia de jogar para as paredes, para os cantos... Como que tu vês a relação do som com o espaço?

$\mathbf{M}$ - É muito importante trabalhar com a fantasia, com a imagem. As imagens são fundamentais para se ter um resultado. E o que eu sempre dizia: "o resultado só acontece com a continuidade de treino! Continuidade de treino é fundamental e, portanto, disciplina é fundamental”. Disciplina em todas as situações, como pontualidade, respeito com os outros colegas, não é? Tanto que nas minhas aulas, não sei se te lembras, mas ninguém se atrasava! Normalmente nossas aulas começavam bem pontuais, porque eu fechava a porta, (risos) tipo Maria Helena Lopes. Mas é importante, porque o trabalho é em conjunto. Quanto a essa idéia da imagem: sempre criar a imagem de que o som é projetado para longe e que nos envolve. Não é só para frente! Mas é a ideia de ondas sonoras se ampliando em volta. E isso é importante então a ideia de apoio, dentro da minha linha de trabalho de voz, de costas largas, costas presentes. Porque isso é o que nos dá uma base, diafragma apoiando para baixo, mas... costas... costas... Essa idéia de ser envolto com som!

E - E tinha também uma coisa com os olhos, o sorriso interior! (risos)

M - Isso eu sempre digo para cantar: sorriso interior! Não tão sério! Não tão sério! O sorriso interior levanta a máscara, abre para a percepção auditiva. Abre os olhos, cria brilho no olhar e conseqüentemente brilho nos sons.

$\mathbf{E}$ - Eu lembro tanto disso!

M - Mas isso faz muita diferença! E esse relaxamento da língua, também, que as pessoas esquecem bastante no trabalho de voz. Ter espaço interior, não recuar a língua.

E - Marlene, havia princípios específicos que tu trabalhavas? Esses princípios vieram, talvez, do canto? Ou tu organizaste princípios que depois tu seguirias?

M - Olha, eu sempre tentei participar de tudo quanto era oficina possível na época, junto com os meus alunos. Mesmo para ver, às vezes, trabalhos vocais que não deveriam ser feitos, que seriam até prejudiciais. Mas isso faz parte porque a gente tem que ter critérios. O que pode apreender para si e integrar no seu trabalho de voz, e o que não deve ser integrado. Isso é bem importante. Então, eu lia muito. Eu mandei vir muito material da Alemanha, porque era uma língua fácil para mim, e a partir de Theophil Maier, justamente, que foi em $1982,83,84$, esses anos todos eu traduzia os cursos. Ele vinha e eu traduzia os cursos para o Goethe. O que eu aprendi com esse homem foram idéias diferentes, sabe? Ele é um grande pedagogo! Não sei nem se vive ainda, mas... enfim, agora não tive mais contato. E foi muito interessante. O Goethe é importante, nos trouxe Andrea Sipan para um curso enorme que eu fiz que era "Corpo e Voz". Esse rapaz era professor de corpo e voz na Alemanha, e mostrou vídeos do seu trabalho lá, onde havia aquela integração que eu não via no DAD. Uma professora bem velhinha de canto, por exemplo, de voz, dentro das aulas de corpo. Enquanto os alunos faziam suas acrobacias, eles falavam textos. E ela via nos momentos da acrobacia onde é que havia tensão e corrigia justamente. E também vídeos com ela simplesmente assistindo e corrigindo os alunos cantando, mas havia um pianista acompanhador. Ela não se envolvia com isso. Eu nunca fui pianista. Meu trabalho sempre foi voz e flauta doce. Claro que um pouco de teclado para vocalizes. Mas eu me lembro que procurei o professor Hubertus Hofmann no departamento de música e perguntei: tu não tens alunos de acompanhamento que poderiam acompanhar os alunos de canto lá no DAD? Eles podem ter créditos, quem sabe ... Daí diz o professor Hubertus Hofmann, já falecido também: os meus alunos só vem cifrões. Como eu não estava em condições de pagar pianista acompanhante para os alunos do DAD, eu desisti dessa ideia.

$\mathbf{E}$ - Que pena, não é?

M - É. Mas sei lá... Pode ser que essas coisas já tenham mudado... Não sei, mas espero que agora tenha mais integração. Claro que estão fazendo essas óperas agora, isso já é uma integração entre os três departamentos. Isso não havia. Eu me lembro que o que nós fizemos com o Conjunto de Câmara de Porto Alegre fazendo a parte sonora da "A alma boa de Setsuam", de Brecht, que foi dirigido pelo Luiz Paulo Vasconcelos. Foi a única vez que o Conjunto de Câmara de Porto Alegre fez a trilha sonora de uma peça lá do DAD. Ele havia feito também, no tempo em que eu lecionava lá, no início, "A tempestade", de Shakespeare, com os alunos do DAD, 
em que eu fiz a preparação vocal também. Mas agora as coisas são bem diferentes, tem a Inês Marocco fazendo coisas belíssimas...

E - Sim... Professora, sobre a relação entre a parte vocal e a escuta. Como tu vês a importância da escuta? O trabalho com os textos, a atenção do ator...

M - É. Quando nós líamos textos em aula, eu sempre me preocupava com as pausas. Eu dizia: tem que haver silêncio! Vocês têm que assinalar no texto, sempre, uma imagem para cada parte. Cada parte assinalada, o quê a personagem pensava ou poderia estar pensando para dizer aquilo. De que forma? Tentar diversas maneiras diferentes de dizer aquilo. E entre essas ideias, a pausa! O público precisa de uma pausa para ouvir, para entender aquilo que ouviu e criar as suas próprias imagens com aquilo que ouviu. O texto não pode ser decorado. Um texto, primeiro, deve ser lido em silêncio para entendê-lo. Depois assinalar as ideias. Assinalar a forma que poderia ser dito aquilo, daí começar a experimentar. Porque se a pessoa começa decorando, o ouvido se acostuma àquela melodia decorada e aí é muito difícil de sair disso.

$\mathbf{E}-\mathrm{E}$ isso acontece muito, não é?

M - Sim, claro!

$\mathbf{E}$ - Depois o ator não consegue sair daquele registro.

M - É. Então, é importante ler mudo, compreender bem, separar as ideias e tentar criar uma imagem. Uma imagem para cada trecho. Isso eu fazia também para as músicas quando eu cantava no conjunto. Cada trecho, uma imagem. Como tentar expressar? Porque não adianta ter uma técnica vocal boa e dizer: oh, que linda voz. Sim, mas canta notas? O que se vê muito por ai é cantar notas, mas e a expressividade, que é o mais importante? Eu sempre dizia: dizer um texto cantando! Isso que é importante para o canto. Dizer um texto cantando.

E - E falar um texto... pensando. (risos).

$\mathbf{M}$ - Sim, sim, com imagens. Com imagens, porque aí acontecem coisas bem interessantes. Eu trabalhei muito também com o "Falus e Stercus", com a Luciana Paz e com o Alexandre Vargas, em "A escrita de Borges". O que nós trabalhamos!! E "O vão da escada” da Luciana, da Luca... Então, tem pessoas bem especiais que realmente se trabalham. Mas isso, ultimamente eu vejo um pouco raro...

E - Tu sugerias também de marcar com cores o texto...

M - Sim. Podia ser com cores, podia ser com desenhos, ascendentes ou descendentes. Retardando, ficando mais lento. Ou, quem sabe, apressar aqui um pouco mais. Volumes diferentes.

E - Isso! E eu me lembro que davas muita importância para que a gente realmente marcasse o texto, no papel, que se trabalhasse com essa parte visual!

$\mathbf{M}$ - Sim, sim, eu acho muito importante porque tem pessoas que têm mais memória visual do que memória auditiva. E também a partitura de gestos. A partitura de gestos é que leva a memorizar o texto, penso eu. Isso pelo menos eu via no trabalho da Maria Helena Lopes. "O império da Cobiça" foi um trabalho que eu fiz com a Maria Helena Lopes, no grupo Tear, e estreou em São Paulo, e... nossa! Eu até ganhei uma menção honrosa pelo trabalho vocal. Mas isso porque os atores eram inteligentes! (risos). Eram atores muito inteligentes! Era a Ciça Reckziegel, Sergio Lulkin... meu deus... A Nora Prado, a Marta Biavaski. Era uma turma...

E - Era um elenco de primeira!

M - O Robertinho Camargo... E sabes que muitos deles, depois, fizeram a orientação cênica do Conjunto de Câ mara de Porto Alegre. O primeiro foi o Roberto Camargo, que me ajudou. Ajudou muito nos nossos trabalhos. O Birindelli, ... muitos alunos! Agora eu posso esquecer alguns nomes...

E - Sim, mas é bom a gente ter essa idéia das colaborações que aconteceram... E tu falaste um pouco no início, mas eu gostaria de voltar a falar sobre a relação entre a palavra falada e a palavra cantada.

$\mathbf{M}$ - Deveriam ser trabalhas juntas! Eu acho importantíssimo falar, cantar, falar, cantar, é uma coisa só! 
E não perceber uma pessoa que quando canta não parece ser mais a mesma pessoa que está falando. Alguma coisa está falha! Provavelmente aí, então, a técnica do canto.

E - E no que difere, então, a técnica do canto e a técnica da fala?

$\mathbf{M}$ - É como eu digo, tem inúmeras linhas diferentes. Eu sempre trabalhei na linha de voz natural, para música de câmara. Bastante oposta à linha de canto lírico italiano. Não que eu não goste, mas nunca tive voz para cantar ópera, então eu cantava música de câmara! E também era o que eu mais praticava, principalmente com a Madeleine Ruffier! Isso aí foi uma escola para quem trabalhou com essa mulher, que é inacreditável. Ela era uma grande artista, muito sensível.

E - Onde que isso se coloca de maneira diferente no corpo? É uma atitude diferente? É o modo de usar a voz...

M - Na linha natural de voz, cantar o mais parecido com a voz falada. Não fazer artifícios para cantar. Então tem que ser uma coisa integrada! Tanto que, no conjunto de câmara, todos os músicos que passaram pelo conjunto, dezenas e dezenas de músicos, todos eles faziam aulas comigo. Nunca cobrei por essas aulas, porque eu achava que era o meu trabalho. Eu queria que todos, quando cantassem, um refrão que fosse, cantassem na mesma linha de voz. Isso para elevar o nível do trabalho. E eu acho que também é importante para o músico instrumentista ter essa consciência, sabe? De presença cênica. Eu tenho, por exemplo, uma das minhas filhas... (Eu tenho quatro filhos: Roberto, que é diplomata; a Márcia, que é psicóloga; o Renato, que é dentista; e a Marlize, que é violoncelista barroca). A Marlize, que já mora há doze anos na Itália, em Milão, onde é violoncelista, participou oito anos do Conjunto de Câmara de Porto Alegre. E faz uma diferença incrível esse aprendizado que ela teve, de presença cênica. Isso, lá na Itália e na Suíça, onde ela anda tocando, é muito apreciado, porque ela olha para os outros instrumentistas e cantores, ela respira junto, ela sorri. Não é aquela coisa séria do instrumentista...

E - Voltada para dentro com seu instrumento.

$\boldsymbol{M}$ - É, justamente! Que é bem autista, como eu digo (risos). Mas, enfim... É necessário olhar para os outros, respirar junto! E essa presença cênica é tanto para o instrumentista quanto para um músico cantor. É a mesma coisa: ator, bailarino... Um sorriso interior para o bailarino é importantíssimo! O respirar com as costas, ter costas presentes, largura de costas...

$\mathbf{E}$ - Com certeza. Marlene, tu sabes que existe um certo mito na cidade, entre as pessoas que foram teus alunos, sobre alguns exercícios que todo mundo sempre lembra, sabe?

$\mathbf{M}$ - (risos). Eu repetia muito! Mas acontece que é a continuidade de treino que dá resultado!

E - Sim. Tinha aquela seqüência: o bico sorriso; a língua bem mole... Todo esse aparato bucal, não é?

$\mathbf{M}$ - Sim, relaxamento! Importante! Relaxamento da mandíbula, da língua, o bocejo interior, a abertura interior para o som fluir mais solto. E sirenes, muitas sirenes!

E - Envolvia todo corpo!

M - Sim. A sirene era justamente para pensar, ter a imagem do trajeto do som. Que o som não se propague reto, e sim que ele faça curva pelo céu da boca e seja lançado pelos olhos! Boca na altura dos olhos! Para que o som corra longe, e esteja colocado. E isso é tanto para voz falada quanto cantada. Para mim não tem diferença!

$\mathbf{E}$ - Sim, e esse é o desafio!

M - É. Não escurecer a voz para cantar. Cantar com a sua própria voz. É lógico que existem, depois, trabalhos diferenciados que a gente tem que fazer para personagens diferentes, aí temos que ter muito cuidado. Por isso é importante conhecer a sua própria voz, porque se experimenta um outro ressonador, uma outra forma de emitir a voz, tem aquele gancho para voltar a sua própria voz porque conhece a sua própria voz!

E - E o que tu sugeres para os atores para conhecerem a sua própria voz?

$\mathbf{M}$ - É, teria que ser feito um pequeno trabalho básico, não é? 
$\mathbf{E}$ - Básico e continuado.

M - Básico e continuado. De alongamento, relaxamento, respiração, ressonância... Fizemos muito ressonância em postura de bebê, do ioga, para encontrar justamente o trajeto do som. Como se o som partisse do centro do corpo e passasse pela coluna vertebral, pelo céu da boca em direção ao chão, a curva do som.

E - Assim como tu usavas o tai-chi, tu usavas também o ioga?

M - É, alguns exercícios também.

$\mathbf{E}$ - E tem mais alguma outra fonte dos exercícios corporais?

$\mathbf{M}-$ Sim... é que quando eu era jovem, eu fiz quatorze anos de ioga com o Cosmelli, depois fiz dezessete anos de artes marciais chinesas com o Rubem. Mais o Tai-chi, e fiz até kathis de espada. Aí meus joelhos ficaram bem baleados, então eu só faço agora academia, pilates... (risos)

$\mathbf{E}$ - Mas não para nunca, não é?

$\mathbf{M}$ - Estou com setenta anos, então vou fazendo academia e pilates de momento. (risos)

E - Bem, eu ainda gostaria de voltar numa questão que abordamos no início, sobre como tu vês a passagem das disciplinas de Técnica Vocal para Expressão Vocal?

M - Sim. Técnica, o pessoal acha que é só vocalizes. Mas não é só isso! Antes de fazer vocalizes, tens que conhecer tudo isso! A conscientização da postura, da respiração, da abertura interior, da colocação da voz. Tudo isso vem antes! Exercícios de relaxamento de língua e tudo mais. E quando começar a fazer vocalizes, fazer só no centro da voz, onde é fácil para cada um. E descobrir onde passa da voz falada para a voz cantada, naquela região. E só depois, com o tempo, ir para os extremos, para o agudo e para o grave. Isso é importante! Não adianta nada começar a fazer vocalizes assim a la louca, para cima e para baixo, de qual quer jeito, sem ter a consciência da abertura, do relaxamento, enfim...

$\mathbf{E}-$ E tens ido ao teatro? O que estás achando?

M - Tenho. Olha, o trabalho do "Os homens do triangulo rosa" foi muito sensível, não é? Esse é um trabalho belíssimo. Aquela dupla... O Marcelo Ádams e a Margarida, foram meus alunos no DAD. O Fred e o Marcelo estão muito bem. Muito bem. Aquilo é um trabalho sensível. É, é complicado. O que eu via nos últimos anos, até no Conjunto, é que as pessoas querem participar de tudo. Aparecer em tudo, também. Às vezes o problema pode até ser financeiro, mas nem sempre é isto. E daí fazem tudo superficial! Não chegam a se trabalhar mesmo. Isso aí é uma diferença para os atores que se trabalham, como o trabalho da "Usina do Treinamento do Ator". Eu acho que cinco ou seis, nem sei quantas peças eu fiz em conjunto com Flávio Oliveira. Flávio Oliveira fazendo a composição e eu fazendo a parte de voz. É um trabalho muito rico com pessoas que a gente vê que tem uma continuidade de trabalho e que se trabalham.

E - Então se tu fosses dar um conselho para os estudantes de teatro e dança...

$\mathbf{M}$ - É a disciplina! Disciplina é fundamental! Treinamento com continuidade é fundamental. Se aprofundar naquilo que fazem. Não fazer superficialmente muitas coisas ao mesmo tempo. Estudar muito! Várias línguas! E ler bastante, pois um ator deve ter cultura geral. Assim, eles terão um imaginário muito mais enriquecido.

E - Certíssimo! Concordo (risos). Acho que encerramos aqui então...

M - Não sei se isso para ti faz alguma diferença...(risos)

E - Sim!! Para mim e para muita gente, vai fazer com certeza! Eu te agradeço muito! 